\title{
You can hide but you can't run: apparent competition, predator responses and the decline of Arctic ground squirrels in boreal forests of the southwest Yukon
}

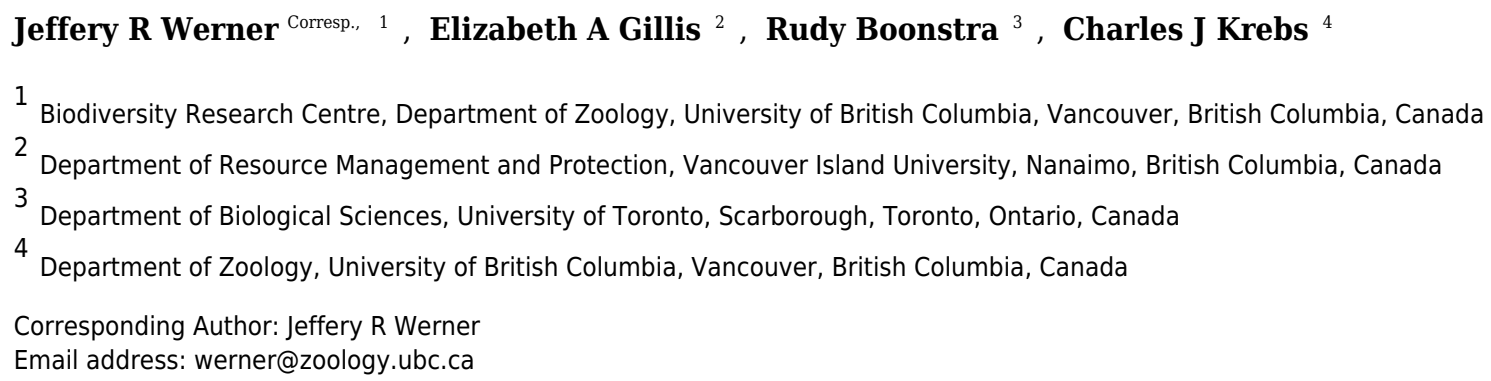

Throughout much of North America's boreal forest, the cyclical fluctuations of snowshoe hare populations (Lepus americanus) may cause other herbivores to become entrained in similar cycles. Alternating apparent competition and indirect mutualism via prey switching are the mechanisms behind this interaction. Our purpose is to document a change in the role of indirect interactions between sympatric populations of hares and arctic ground squirrels (Urocitellus parryii plesius), and to emphasize the influence of predation for controlling ground squirrel numbers. We used mark-recapture to estimate the population densities of both species over a 25-year period that covered two snowshoe hare cycles. We analysed the strength of association between snowshoe hare and ground squirrel numbers, and the changes to the seasonal and annual population growth rates of ground squirrels over time. A hyperbolic curve best describes the per capita rate of increase of ground squirrels relative to their population size, with a single stable equilibrium and a lower critical threshold below which populations drift to extinction. The crossing of this unstable boundary resulted in the subsequent uncoupling of ground squirrel and hare populations following the decline phase of their cycles in 1998. The implications are that this sustained Type II predator response led to the local extinction of ground squirrels. When few individuals are left in a colony, arctic ground squirrels may also have exhibited an Allee effect caused by the disruption of social signalling of approaching predators. 
1 Title: You can hide but you can't run: apparent competition, predator responses and the decline of

2 Arctic ground squirrels in boreal forests of the southwest Yukon.

3 Indirect effects mediate predator response in an arctic herbivore

4 Jeffery R. Werner ${ }^{\mathrm{A}, \mathrm{D}}$, Elizabeth A. Gillis ${ }^{\mathrm{B}}$, Rudy Boonstra ${ }^{\mathrm{C}}$, and Charles J. Krebs ${ }^{\mathrm{A}}$

5 A Department of Zoology, University of British Columbia, 6270 University Boulevard,

6 Vancouver, BC V6T 1Z4, Canada.

$7 \quad$ B Department of Resource Management and Protection, Vancouver Island University, 900 Fifth

8 St, Nanaimo, BC V9R 5S5, Canada.

$9{ }^{\mathrm{C}}$ Department of Biological Sciences, University of Toronto Scarborough, 1265 Military Trail, 10 Toronto, ON M1C 1A4, Canada.

11 D Corresponding author. Email: werner@zoology.ubc.ca 


\section{Abstract}

13 Throughout much of North America's boreal forest, the cyclical fluctuations of snowshoe hare populations (Lepus americanus) may cause other herbivores to become entrained in similar

15 cycles. Alternating apparent competition via prey switching followed by positive indirect effects

16 are the mechanisms behind this interaction. Our purpose is to document a change in the role of

17 indirect interactions between sympatric populations of hares and arctic ground squirrels

18 (Urocitellus parryii plesius), and to emphasize the influence of predation for controlling ground squirrel numbers. We used mark-recapture to estimate the population densities of both species over a 25-year period that covered two snowshoe hare cycles. We analysed the strength of association between snowshoe hare and ground squirrel numbers, and the changes to the seasonal and annual population growth rates of ground squirrels over time. A hyperbolic curve best describes the per capita rate of increase of ground squirrels relative to their population size, with a single stable equilibrium and a lower critical threshold below which populations drift to extinction. The crossing of this unstable boundary resulted in the subsequent uncoupling of ground squirrel and hare populations following the decline phase of their cycles in 1998. The implications are that this sustained Type II predator response led to the local extinction of ground squirrels. When few individuals are left in a colony, arctic ground squirrels may also have exhibited an Allee effect caused by the disruption of social signalling of approaching predators. 


\section{Introduction}

The comprehensive role that snowshoe hares (Lepus americanus) play in the food web dynamics of North America's boreal forest epitomizes the notion of "foundation species" (sensu Dayton, 1972) who by virtue of their abundance and influence on other species helps define an entire ecological community (Sinclair \& Krebs, 2001). In particular, the cyclic oscillating abundance of the hare and its predators (e.g., lynx, coyotes, great horned owls) is central to our understanding of how predators influence the population dynamics of other common prey species (Boutin et al., 1995).

Predator-mediated "apparent competition" (Holt, 1977) between two prey can occur when at least one natural enemy is held in common and, that enemy enables the numbers of one species to negatively influence the abundance of another. In the case where such negative influences are not reciprocated between both prey species, 'asymmetric' apparent competition can lead to a variety of outcomes that depend on the intrinsic nature of the predator-prey relationship (Sinclair \& Pech, 1996; DeCesare et al., 2010). Additionally, when predator-prey systems are routinely not at equilibrium, the primary prey species may achieve rapid increase leading to predator satiation and a temporary decrease in the per capita predation rate for both prey species (Holt \& Lawton, 1994; Abrams \& Matsuda, 1996). The effects of predator satiation, however, are limited to short time scales, because the higher availability of prey will trigger a numerical response in the predator over subsequent predator generations (Holt \& Kotler, 1987). Although the influence of such positive indirect effects is generally fleeting, this effect may recur when population densities of one prey show cycles that result in repeated satiation of the shared predators and reduced predation on the secondary prey species (Abrams et al., 1998). The periodic intensification and relaxation of predation is implicated in the synchronous population fluctuations of voles and either hares (Angelstam et al. 1984) or grouse (Hörnfeldt et al. 1986) in Sweden, voles and shrews in northern Europe (Hansson 1984; Korpimäki et al. 2005), and small rodents and ground 
57 nesting birds in northern Eurasia (Sutherland 1988) and the high arctic (Bêty et al. 2002). The

58 alternating influence of apparent competition during the decline phase of the cycle, followed by

59 positive indirect effects leading to temporary escape from predator regulation during the increase

60 phase, are sufficient conditions for synchronous cycling of primary and secondary prey (Abrams

61 et al., 1998; Norrdahl \& Korpimäki, 2000).

62 In North Americadramatic fluctuations in hare density are also known to entrain other prey

63 species into cycles of similar duration (Boutin et al., 1995; Krebs, Boutin \& Boonstra, 2001). The

64 best documented case is that of the arctic ground squirrel (Urocitellus parryii; hereafter AGS),

65 whose numbers in the SW Yukon varied in synchrony with hares for over three decades (Werner

66 et al., 2015a). The putative mechanism for these coincident patterns in abundance is prey-

67 switching, from hares to ground squirrels, during the decline phases of the hare cycle (Boutin et

68 al., 1995; Byrom et al., 2000; Krebs et al., 2014).

69 These forest ground squirrel populations and their cyclic behaviour have been investigated

70 since the 1970's (Green, 1977; Hubbs \& Boonstra, 1997; Byrom et al., 2000; Karels et al., 2000;

71 Gillis et al., 2005; Donker \& Krebs 2012). From the 1973 to 1999 increases among AGS have

72 been stopped by declines that recur with near decadal regularity. However, after 2000, AGS

73 populations declined rapidly at lower elevations ( $\sim 900 \mathrm{~m}$ asl) in the Kluane region (Donker \&

74 Krebs, 2011), and colony extirpation is now widespread throughout similar habitats of the

75 southern Yukon (colony occupancy $=4.2 \%$; Werner et al. 2015a Table 1). The range of this

76 historically ubiquitous herbivore appears to have contracted over the course of a decade. Werner

77 et al. (2015a) hypothesized that this abrupt shift in squirrel abundance, followed by a prolonged

78 phase of very low numbers, was diagnostic of predator regulation (i.e., a 'predator pit' whereby a

79 prey population is maintained at a lower stable equilibrium point well below carrying capacity).

80 However, no direct evidence to support this claim was offered at that time. Here we test whether 
81 the observed population dynamics of AGS are consistent with patterns predicted by predator-prey

82 theory.

83 To predict whether this historically common herbivore (Boonstra et al., 2001) might regain

84 a foothold in this system requires an explicit understanding of the predator response, especially as

85 it relates to low prey density (Sinclair \& Krebs, 2002). In cases where most prey mortality is

86 caused by predation, the predator response can be determined by inspection of the instantaneous

87 rates of change in the prey species over a realistic range of prey densities. Such analyses across a

88 wide range of taxa (Messier, 1994; Sinclair et al., 1998) confirm two general categories of4

89 predator response curves predicted by predator-prey theory (Holling, 1959; Holling, 1973;

90 Sinclair \& Pech, 1996). Where predators suppress but do not eliminate prey at low density (Type

91 III predator response; Figure 1), persistence of the prey species is possible, as is the potential for

92 population recovery in the absence of harmful stochastic events or strong fluctuations in food

93 availability. Even where localised extirpations have occurred, habitat recolonization via

94 immigration is possible. In contrast, when predators continue to consume prey at low prey

95 availability (Type II predator response; Figure 1) local extinction may be inevitable.

96 Discriminating which of these two classes of predation are in operation is an important first step

97 towards ascertaining the fate of AGS in the boreal forest ecosystem.

98 Our purpose is to document a change in the strength of indirect interaction between

99 sympatric populations of hares and arctic ground squirrels and to clarify the recent influence of

100 predation in controlling ground squirrel numbers during the later stages of their disappearance.

101 Both of these aims are met in this paper by analyzing over two decades of long-term population

102 census data collected for hares and AGS in the Kluane region of the SW Yukon. Strong

103 correlation between hare and ground squirrel numbers across a wide range of hare densities is the

104 expected outcome of asymmetric apparent competition (Holt, 1977). Furthermore, the population

105 trajectory of the ground squirrels at various population densities provides useful information

106 concerning the dynamics of the predation at low prey numbers (Sinclair et al., 1998). We the 
107 following hypotheses to account for the observed changes in ground squirrel abundance over a

108 25-year period:

109 Based on a visual inspection of census data we hypothesized a Type III predator response

110 (Figure 1). This hypothesis maintains that AGS populations are regulated at low densities by

111 predators but not regulated by predators at high density (Sinclair \& Pech, 1996). This would

112 explain the apparent shift in AGS abundance to a persistent lower population size after 2000 (i.e.

113 a predator pit). Predictions are that the summer (May-August) per capita growth rate of the prey

114 plotted over prey density will exhibit two positive equilibrium densities separated by a boundary

115 threshold. The alternative hypothesis is that the predator response is Type II. AGS populations are

116 unstable at low density (de-regulated by predation) but escape predation at high density. This

117 hypothesis predicts the existence of a single upper stable population equilibrium and a single

118 lower unstable boundary below which prey density declines towards extinction (Figure 1).

119 We additionally hypothesized that AGS populations were, at all times, governed by predator-

120 mediated competition with hares followed by repeated escape from predator control. This

121 hypothesis predicts a singular association between the annual census data of hares and ground

122 squirrel throughout the monitoring period. A priori knowledge of the system indicates that this is

123 quite likely (Karels et al., 2000; Sinclair \& Krebs, 2001). However, the correlation dynamic may

124 also have weakened with time. The alternative hypothesis is therefore that a phase-change

125 occurred after 2000 , causing the system to shift from predator-mediated competition to a new

126 state unaffected by hare numbers. This 'multi-state' alternative predicts an uncoupling in the

127 strength of correlation between hare and squirrel density after 2000

128 The distinguishing predictions for these hypotheses can be tested, given that two

129 assumptions are correct: 1) changes to AGS numbers during the active season are not affected by

130 overwinter mortality (as might' be the case if using annual census data only). 2) The bulk of

131 active season mortality can be attributed to predation. The first statement is axiomatic and the

132 second supported by the literature. In the boreal forest $93-100 \%$ of active-season (summer) losses 
133 of radio telemetered AGS are confirmed predator mortalities (93\% Hubbs \& Boonstra, 1997;

134 96\% Byrom et al., 2000; 100\% Donker \& Krebs, 2012; 100\% Werner et al., 2015a).

135 Methods

$136 \quad$ Study Species

137 The arctic ground squirrel is a burrowing, semi-fossorial polygynous sciurid (McLean,

138 1981) inhabiting arctic and subarctic regions of North America and Russia (Naughton, 2012).

139 They are typically found in open meadows and tundra, but one of the unique features of their

140 geographic distribution is the extension of their range into the boreal forests of the Yukon and

141 NW British Columbia. Squirrels hibernate for 7-9 months (September/October through April);

142 the remaining active-season is short and individuals must reproduce and gain substantial mass

143 (energy reserve) during this time (Buck \& Barnes, 1999). Juvenile squirrels are born in May but

144 remain in the natal burrow for nearly one month before emerging (with females being philopatric

145 and males dispersing) to establish a territory, and gain sufficient mass to survive winter

146 hibernation (Carl, 1971; Lacey, 1991; Sheriff et al., 2013).

147 In northern ecosystems this common small mammal functions as an important prey item

148 (Hubbs \& Boonstra, 1997), herbivore (Boonstra et al., 2001) and as an ecological engineer (Price,

149 1971). Their distribution drives the abundance and spatial arrangement of other ecosystem

150 constituents from carnivores to plant communities (Wheeler \& Hik, 2012). In the SW Yukon

151 ground squirrels are an important alternate food source for mammalian and avian predators such

152 as the coyote (Canis latrans), lynx (Lynx lynx), Northern goshawk (Accipiter gentilis) and Red-

153 tailed hawk (Buteo jamaicensis) (Doyle \& Smith, 1994; O’Donoghue et al., 1998a,b).

$154 \quad$ Study area

155 The area is in the rain shadow of the St. Elias Mountains and receives a mean annual

156 precipitation of ca. $230 \mathrm{~mm}$, mostly falling as rain during the summer months, but including an

157 average annual snowfall of about $100 \mathrm{~cm}$ (Krebs, Boutin \& Boonstra, 2001). Squirrel and hare

158 data were collected on two 9-Ha trapping grids, located several kilometers apart ( $\sim 900 \mathrm{~m}$ above

159 sea level (asl)) $\left(61^{\circ} 00^{\prime} 38^{\prime \prime} \mathrm{N}, 138^{\circ} 11^{\prime} 31^{\prime \prime} \mathrm{W}\right.$ and $\left.60^{\circ} 55^{\prime} 53^{\prime \prime} \mathrm{N}, 137^{\circ} 58^{\prime} 25^{\prime \prime} \mathrm{W}\right)$. These grids were

160 dominated by white spruce forest (Picea glauca), willow (Salix spp.) or bog birch (Betula 
161 glandulosa) thickets, and occasional aspen stands (Populus tremuloides) (see Boonstra et al.,

1622001 for detailed trap locations and Turkington et al., 1998, 2002 for regional descriptions).

$163 \quad$ Population Estimates

164 Squirrels and hares were trapped twice yearly (May and August) at two sites (GPC and

165 Chitty grids; Boonstra et al., 2001) for 25 consecutive years (nearly 3 hare cycles; 1990-2015).

166 The methods of data collection are fully described in Boonstra et al. (2001). Population density

167 estimates were obtained by mark-recapture methods (described below). Each mark-recapture

168 session consisted of between two (typically) or four (in situations of low AGS/hare density)

169 consecutive days of trapping in May/August for AGS and April/October for hares.

170 Squirrels traps were set at $0800 \mathrm{~h}$, checked every $1.5 \mathrm{~h}$, and closed by $1230 \mathrm{~h}$ each trapping

171 day. Arctic ground squirrels are highly trappable and recapture rates were high (>80\%). Squirrels

172 were live-trapped on two grids each with 50 traps spaced $30 \mathrm{~m}$ apart in a $10 \times 10$ pattern with

173 traps placed at alternate grid stations. Live traps $(14 \mathrm{~cm} \times 14 \mathrm{~cm} \times 40 \mathrm{~cm}$; Tomahawk Live Trap

174 Co., Tomahawk, Wisconsin, USA) were baited with peanut butter. Upon first capture, squirrels

175 were transferred to a mesh bag, where they were then tagged in both ears with unique monel No.

176 1005-1 tags (National Band and Tag Co., Newport, Kentucky, USA), weighed (Pesola spring

177 scale $\pm 5 \mathrm{~g}$ ), sexed, and measured for structural size (zygomatic arch width) using a 150mm metric

178 dial reading caliper.

179 Snowshoe hare live-traps were pre-baited with alfalfa cubes for 3-5 days prior to being set.

180 Trapping sessions consisted of 2-3 nights of trapping within a 5-day period in spring (early April)

181 and autumn (October). The traps were set at 2200 hours and checked at 0600 hours to minimise

182 the length of time hares were detained. Upon capture, each hare was identified to sex, weighed

183 with a Pesola spring scale $( \pm 10 \mathrm{~g})$, its right hind foot length was measured (as an index of body

184 size), and its right ear was tagged (No. 3 Monel tags; National Band and Tag Co., Newport,

185 Kentucky, USA). Trapping and handling protocols were approved by the University of British

186 Columbia Animal Care Committee in accordance with the guidelines of the Canadian Council on 
187 Animal Care (NIAUT certificate \# 5740 - 13) and all research was sanctioned under the Yukon

188 Scientist and Explorers Research permit (License \# 14-10S\&E, file \# 6800-20-43).

189 Analysis

190 Population estimates and standard errors were estimated using a mark-recapture

191 heterogeneity (jackknife) model (Pollock et al., 1990) from Program Capture (White et al., 1982;

192 Rexstad and Burnham, 1991). We calculated the effective sample area (to produce a density

193 estimate) for each trapping period by adding a boundary strip to the edges of the trapping grid

194 equal to half the mean maximum distance moved (Otis et al., 1978; Krebs et al., 2011). This

195 method performs equally well to other density estimates for small mammals (Krebs et al., 2011).

196 Rates of population increase were calculated for seasonal and annual time intervals. Yearly rates

197 based on spring census data were used to generalise annual patterns of change over time. To

198 distinguish between possible Type II and Type III predator relationships, the instantaneous rates

199 of increase were calculated for each active-season (May-August). The shape of the predator prey

200 relationship was determined by plotting the instantaneous per capita rate of change for AGS

201 between $\mathrm{N}_{t}$ and $\mathrm{N}_{\mathrm{t}+1}(\mathrm{dN} / \mathrm{dT} / \mathrm{Nt})$ over population density at $\mathrm{N}_{\mathrm{t}}$ (Sinclair et al., 1998). Data from

2021990 and 1999 were excluded from this plot because these years coincide with intense prey-

203 switch events that result in total population collapse (such perturbation events are treated

204 separately when analysing cyclic dynamics; Sinclair \& Krebs, 2002). Because the application of

205 goodness-of-fit curves to time series data is inappropriate, regression curves are used only to

206 predict the regions where rates of change are zero. The slope of the regression curve where it

207 crosses the zero line was used to classify stable equilibria and/or unstable boundaries.

208 All other statistical analyses were calculated using the programs JMP version 4.0 (SAS

209 institute Inc., Cary, North Carolina, USA) or StatistiXL version 1.8. We measured correlation

210 between hare and AGS densities for the time periods 1990-2011 and 2012-2014 by calculating

211 the coefficient of determination using ordinary least squares regression. We used the Chow Test

212 (Chow, 1960) to test if the coefficients of linear regression for each time period were equal. This 
213 is used in the analysis of time series data to test for structural breaks in the correlation dynamic of

214 a single explanatory variable (Chow, 1960). Mann-Whitney U-tests were used to compare

215 median population densities where data were not distributed normally.

216 Results

217 Both hare and ground squirrel population density were marked by repeated fluctuations

218 (Figure 2) that were coincident between 1990-2001 $\left(\mathrm{R}^{2}=0.69\right.$; Figure 3$)$ but not coincident

219 between 2002-2013 $\left(\mathrm{R}^{2}=0.01\right.$; Figure 3$)$. The amount of variation in squirrel density explained by

220 hare density ( $\mathrm{R}^{2}$ value) differed significantly between the two time periods (Chow Test:

$221 \mathrm{~F}_{2,14}=33.4, \mathrm{p}<0.001$; Figure 3). After 2000, AGS populations failed to increase despite a modest

222 rise in hare numbers including peaks hare abundance in 2005 and again in 2015. Mean density for

223 the period preceding the year 2000 was significantly larger (by one order of magnitude) than for

224 the interval proceeding the pivotal population decline $(U=41, n 1=24, n 2=26, p<0.01)$. Figure 4

225 illustrates two patterns: first, the annual rate of change for the decline phase of the hare cycle

226 follows a different track from that for the increase (circular pattern to the right); and second, the

227 overall dynamic changed from visually circular to unstable below a threshold density of 0.5 AGS

228 individuals/ha (Figure 4).

229 To estimate the predator response, the instantaneous rates of per capita population growth

230 for the active-season period (May-August) were plotted against spring population density. Over

231 the entire range of densities recorded for AGS the density dependence relationship is curvilinear

232 (Figure 5), and conforms to a Type II predator-prey relationship (Figure 1). The rate of population

233 change crosses the zero line at two specific density locations. The upper stable point in Figure 5

234 is equivalent to point $\mathrm{C}$ in Figure 1; here density dependent processes act to maintain squirrel

235 density at $\sim 2 / \mathrm{Ha}$, which is the historical carrying capacity (Werner et al., 2015a). The negative

236 downward slope of the population function at point $\mathrm{C}$ is indicative of population regulation (Sibly

237 and Hone 2002). In contrast, the lower threshold $(\sim 0.25-0.5 / \mathrm{Ha})$ is an unstable boundary below

238 which AGS abundance can decline toward extirpation (Figure 5). Because density dependence 
239 varies from values which are weakly positive to negative, there is little compensation for

240 stochastic effects at or near this threshold.

241 Discussion

242 Study limitations

243 Our aim is to infer the nature of the predator-prey relationship and to assess prospects for

244 population recovery. A variety of a priori reasons exist to expect predation to show strong signals

245 through the noise of contingent events in this part of the boreal forest (Krebs et al. 2001, Donker

246 \& Krebs 2012; Werner et al., 2015b). However, the possible contribution of Allee Effects (Allee,

247 1931) to the extinction process must first be considered. Social processes can cause per capita

248 rates of change similar to those seen in Type II predator interactions, but without recourse to

249 predation (Odum \& Allee, 1954). The range of mechanisms that could contribute to Allee Effects

250 for AGS include lower mate finding success (Stephens \& Sutherland, 1999), lowered

251 reproduction resulting from poor body condition, reduced group vigilance and alarm calling

252 (Stephens \& Sutherland, 1999), the loss of conspecific cues for habitat choice (Reed \& Dobson,

253 1993), and other forms of behavioural dysfunction (Brashares, Werner \& Sinclair, 2010).

254 Because the mating system of the arctic ground squirrel is polygynous, mate-finding

255 limitation caused by skewed sex ratios at low population size is not likely to cause inverse

256 density dependence. It has been shown that adult females from this population over the same time

257 period were in good hibernating condition by autumn (Werner et al., 2015b) and, because these

258 females hibernate singly, their reproductive output the following spring cannot be attributed to

259 any socially-mediated or density related process prejudicial to reproduction. Conspecific

260 attraction may play a role in low rates of recolonization but this process will not hasten

261 population decline because resident females are philopatric (Carl, 1971) and site abandonment

262 has never been observed. However, the lost benefits of predator detection and signalling

263 behaviour common to ground squirrels (Sherman, 1977) and other social rodents (Blumstein,

264 2007) remains a possible contributing factor. Be it noted however that although Allee effects may 
265 aggravate population declines and/or constrain population recovery, they are inadequate to trigger

266 such a decline (i.e., operates at low density).

267 It has been shown theoretically (Holt, 1977) and empirically (Pech et al., 1995) that when

268 the abundance of primary prey increases, the attendant increase in predators results in a decline in

269 the abundance of secondary prey. However, when the preferred prey undergoes dramatic cycling,

270 shifting predator preferences at different phases in this cycle can result in similar fluctuations and

271 coincident declines in the abundance of secondary prey (Norrdahl \& Korpimäki, 2000). The

272 strongly asymmetrical nature of indirect effects purported here (changes in hare abundance cause

273 similar changes in ground squirrel but not vice versa) precludes using AGS extirpations as a

274 natural test of these indirect effects. Only the removal of hares could serve as such a test.

275 However, the large and nearly coincident fluctuations in both hare and ground squirrel numbers

276 (Figure 2) coupled with the observation that ground squirrels do not cycle in the absence of hares

277 (Donker \& Krebs, 2011) provide compelling evidence for the existence of these indirect

278 interactions up until the collapse of 2000. Further evidence for the role of predator mediated

279 indirect effects for synchronising population oscillations of these sympatric prey species come

280 from i) detailed studies linking AGS cycles to intensified predation during their decline phase

281 (Hubbs \& Boonstra 1997; Byrom et al. 2000), and ii) the observation that the density, hunting

282 behaviour, and diet of these same predators alter predictably with hare abundance (O'Donoghue

283 et al. 1997, 1998a, 1998b).

Depensatory predation is possible in multi-prey systems where predators persist

irrespective of secondary prey abundance (Holt \& Lawton, 1994). Where a curvilinear (hump-

shaped) density response exists, stochastic population losses are not compensated for by positive

287 density dependent processes at low population size. In such cases of inverse density dependence 288 populations below a certain threshold will trend to extinction (Sinclair \& Krebs, 2002). Here we 
289 demonstrate a type II predator-prey relationship and quantify the critical density threshold

$290(>0.7 / \mathrm{ha})$ necessary for the persistence of AGS in the Yukon boreal forest system where hares are

291 the preferred prey species for a range of predators (O'Donoghue et al., 1998a). The breach of this

292 lower boundary during 1999-2000 is the most likely explanation for the loss of the alternating

293 apparent competition and indirect mutualism with the snowshoe hare, and for subsequent loss of

294 cyclicity in AGS abundance. These findings indicate that, as a secondary prey species, AGS may

295 succumb to depensatory mortality from predator populations that are otherwise sustained by an

296 abundant primary prey (DeCesare et al., 2010). The existence of prey switching during specific

297 periods of the hare cycle further exacerbates this unstable dynamic by reducing the length of time

298 squirrels remain at or near carrying capacity.

299 Upon first inspection, the decade long persistence of ground squirrel numbers at very low

300 densities appears to corroborate a lower stable equilibrium characteristic of a type III predator

301 interaction (Figure 2). Inspections of this yearly time series prompted Werner et al. (2015a) to

302 hypothesize the possible existence of a predator pit at low numbers. However, when changes to

303 population density are limited to marked individuals caught at the beginning and end of each

304 active-season we find that local populations sometimes dropped to zero in autumn, only to exhibit

305 positive numbers the following spring. The existence of multiple extirpation events on the same

306 trapping grids were effectively obscured in yearly census data because unmarked dispersing

307 immigrants settled into the newly vacant habitat (Donker \& Krebs, 2012). This discrepancy

308 underscores the important fact that the resolution of population census data (annual vs. seasonal)

309 must be fitted to the needs imposed by the research question. In this case it was important to

310 estimate the predator response by restricting our analysis to rates of change for the active-season

311 only.

312 Because density dependent relationships are notorious for their non-repeatable

313 characteristics over time and space (Krebs, 2002) the patterns we report may have limited wider

314 application. However, given widespread concomitant disappearance of AGS from boreal forests 
315 in Kluane (Gillis et al., 2005; Donker \& Krebs, 2011) and much of the low elevation habitats of

316 the southern Yukon (Werner et al., 2015b), the intensification of predation across large areas

317 cannot be discounted as the proximate cause of these patterns. The most recent surveys of Lynx

318 abundance indicate that during the last low phase of the hare cycle (2008-2012) Lynx were more

319 numerous than ever recorded for any previous low (Krebs et al. 2016). In Kluane Lynx focus on

320 alternative prey like red squirrels (O’Donoghue et al., 1998a) during the winter months in years

321 when hares are sparse. Higher predator abundance in advance of the increase phase of the hare

322 cycle makes future indirect mutualism less likely because of the shortened lag in the predators'

323 numerical response.

324 We propose that predation, being the most consistent explanation for population collapses,

325 is the most likely proximate cause of local ground squirrel extinctions in the boreal forests of the

326 SW Yukon. The principle assertions of this paper - the existence of Type II predation and an

327 unstable critical threshold in prey density - is being tested by raising the local density of AGS

328 above 0.7 / ha in a series of experimental reintroductions into formerly occupied habitats within

329 the boreal forest zone (Werner, 2015). This study offers a practical example of how monitoring

330 per-capita rates of change for prey species can be used to infer the predator relationship and, by

331 extension, the range of prey densities where mortality may be depensatory. 


\section{References}

333

334

Abrams PA, Holt RD, Roth, JD. 1998. Apparent competition or apparent mutualism? Shared predation when populations cycle. Ecology 79: 201-212. DOI: 10.1890/00129658(1998)079[0201:ACOAMS]2.0.CO;2.

Abrams PA, Matsuda H. 1996. Positive indirect effects between prey species that share predators. Ecology 77: 610-616. DOI: 10.2307/2265634.

Allee WC. 1931. Animal aggregations: a study in general sociology. Chicago: University of Chicago Press.

Angelstam, P, Lindström E, Widen P. 1984. Role of predation in short-term population fluctuations of some birds and mammals in Fennoscandia. Oecologia 62: 199-208. DOI: 10.1007/BF00379014.

Bêty J, Gauthier G, Korpimäki E, Giroux JF. 2002. Shared predators and indirect trophic interactions: lemming cycles and arctic-nesting geese. Journal of Animal Ecology 71: 8898. DOI: 10.1046/j.0021-8790.2001.00581.x.

Blumstein DT. 2007. The evolution of alarm communication in rodents: structure, function, and the puzzle of apparently altruistic calling. In: Wolff JO, Sherman P, ed. Rodent Societies: an Ecological \& Evolutionary Perspective. Chicago: University of Chicago Press, 317-327.

Boonstra R, Boutin S, Byrom A, Karels T, Hubbs A, Stuart-Smith K, Blower M, Antpoehler S. 2001. The role of red squirrels and arctic ground squirrels. In: Krebs CJ, Boutin S, Boonstra R, ed. Ecosystem Dynamics of the Boreal Forest. Oxford: Oxford University Press, 179214.

Boutin S, Krebs CJ, Boonstra, Dale MRT, Hannon SJ, Martin K, Sinclair ARE, Smith JNM, Turkington R, Blower M, Byrom A, Doyle FI, Doyle C, Hik D, Hofer L, Hubbs A, Karels T, Murray DL, Nams V, O’Donoghue M, Rohner C, Schweiger S. Population changes of the vertebrate community during a snowshoe hare cycle in Canada's boreal forest. Oikos 74: 69-80. DOI: $10.2307 / 3545676$. 
358 Brashares JS, Werner JR, and Sinclair ARE. 2010. Social 'meltdown'in the demise of an island endemic: Allee effects and the Vancouver Island marmot. Journal of animal ecology 79: 965-973. DOI: 10.1111/j.1365-2656.2010.01711.x.

Buck CL, Barnes BM. 1999. Annual cycle of body composition and hibernation in free-living arctic ground squirrels. Journal of Mammalogy 80: 430-442. DOI: http: 10.2307/1383291.

Byrom AE, Karels TJ, Krebs CJ, Boonstra R. 2000. Experimental manipulation of predation and food supply of arctic ground squirrels in the boreal forest. Canadian Journal of Zoology 78: 1309-1319. DOI: 10.1139/z00-055.

Carl EA. 1971. Population control in arctic ground squirrels. Ecology 52: 395-413. DOI: $10.2307 / 1937623$.

Chaneton EJ, Bonsall MB. 2000. Enemy-mediated apparent competition: empirical patterns and the evidence. Oikos 88: 380-394. DOI: 10.1034/j.1600-0706.2000.880217.x.

Chow GC. 1960. Tests of equality between sets of coefficients in two linear regressions. Econometrica: Journal of the Econometric Society 28: 591-605. DOI: 10.2307/1910133.

Dayton PK. 1972. Toward an understanding of community resilience and the potential effects of enrichments to the benthos at McMurdo Sound, Antarctica. In: Parker BC, ed. Proceedings of the colloquium on conservation problems in Antarctica. Lawrence, KS: Allen Press, 8196.

DeCesare NJ, Hebblewhite M, Robinson HS, Musiani M. 2010. Endangered, apparently: the role of apparent competition in endangered species conservation. Animal conservation 13: 353362. DOI: 10.1111/j.1469-1795.2009.00328.x.

Donker SA, Krebs CJ. 2011. Habitat-specific distribution and abundance of arctic ground squirrels (Urocitellus parryii plesius) in southwest Yukon. Canadian Journal of Zoology 89: 570-576. DOI: 10.1139/z11-041.

Donker SA, Krebs CJ. 2012. Evidence for source-sink dynamics in a regional population of arctic ground squirrels (Urocitellus parryii plesius). Wildlife Research 39: 163-170. DOI: 10.1071/WR11167.

Doyle FI, Smith JNM. 1994. Population responses of Northern Goshawk to the 10-year cycle in numbers of Snowshoe Hares. Studies in Avian Biology 16: 122-129. Available at: http://www.fs.fed.us/rm/pubs_other/rmrs_1994_block_w001.pdf 
388

389

390

391

392

393

394

395

Green JE. 1977. Population regulation and annual cycles in the Arctic ground squirrel. M.Sc. thesis, University of British Columbia, Vancouver, B.C., Canada.

Gillis EA, Hik DS, Boonstra R, Karels TJ, Krebs CJ. 2005. Being high is better: effects of elevation and habitat on arctic ground squirrel demography. Oikos 108: 231-240. DOI: 10.1111/j.0030-1299.2005.13535.x.

Hansson L. 1984. Predation as the factor causing extended low densities in microtine cycles. Oikos 43: 255-256. DOI: 10.2307/3544779.

Holling CS. 1959. Some characteristics of simple types of predation and parasitism. The Canadian Entomologist 91: 385-398. DOI: 10.4039/Ent91385-7.

Holling CS. 1973. Resilience and stability of ecological systems. Annual review of ecology and systematics 4: 1-23. DOI: 10.1146/annurev.es.04.110173.000245.

Holt RD. 1977. Predation, apparent competition, and the structure of prey communities. Theoretical population biology 12: 197-229. DOI: 10.1016/0040-5809(77)90042-9.

Holt RD, Kotler BP. 1987. Short-term apparent competition. American Naturalist 130: 412-430. DOI: $10.1086 / 284718$.

Holt RD, Lawton JH. 1994. The ecological consequences of shared natural enemies. Annual review of Ecology and Systematics 25: 495-520. DOI: 10.1146/annurev.es.25.110194.002431.

Hörnfeldt B, Löfgren O, Carlsson BG. 1986. Cycles in voles and small game in relation to variations in plant production indices in northern Sweden. Oecologia, 68: 496-502. DOI: 10.1007/BF00378761.

Hubbs AH, Boonstra R. 1997. Population limitation in arctic ground squirrels: effects of food and predation. Journal of Animal Ecology 66: 527-541. DOI: 10.2307/5947.

Karels TJ, Byrom AE, Boonstra R, Krebs CJ. 2000. The interactive effects of food and predators on reproduction and overwinter survival of arctic ground squirrels. Journal of Animal Ecology 69: 235-247. DOI: 10.1046/j.1365-2656.2000.00387.x.

Korpimäki E, Norrdahl K, Huitu O, Klemola T. 2005. Predator-induced synchrony in population oscillations of coexisting small mammal species. Proceedings of the Royal Society of London B: Biological Sciences 272: 193-202. DOI: 10.1098/rspb.2004.2860.

Krebs CJ. 2002. Two complementary paradigms for analysing population dynamics. Philosophical Transactions of the Royal Society B: Biological Sciences 357: 1211-1219. DOI: $10.1098 /$ rstb.2002.1122. 
420

421

422

423

424

425

426

427

428

429

430

431

432

433

434

435

436

437

Krebs CJ, Boonstra R, Gilbert BS, Reid DG, Kenney AJ, Hofer EJ. 2011. Density estimation for small mammals from live trapping grids: rodents in northern Canada. Journal of Mammalogy 92: 974-981. DOI: 10.1644/10-MAMM-A-313.1.

Krebs CJ, Boonstra R, Boutin S, Sinclair ARE, Smith JNM, Gilbert BS, Martin K, O’Donoghue M, Turkington R. 2014. Trophic dynamics of the boreal forests of the Kluane Region. Arctic 67: 71-81. DOI: 10.14430/arctic4350.

Krebs CJ, Boutin S, Boonstra R. 2001. Ecosystem dynamics of the boreal forest. Oxford: Oxford University Press. Available at: http://www.zoology.ubc.ca/ krebs/kbook.html.

Krebs CJ, Powell T, O’Donoghue M, Jung T, Loewen,V, Gilbert S, Taylor S, Fontaine A, Boonstra R, Boutin S, Kenney AJ. 2016. The community ecological monitoring program annual data report 2015. Available at: http://www.zoology.ubc.ca/ krebs/kluane.html.

Lacey EA. 1991. Reproductive and dispersal strategies of male Arctic ground squirrels (Spermophilus parryii). D. Phil. Thesis, University of Michigan, USA.

McLean IG. 1981. Social ecology of the Arctic ground squirrel Spermophilus parryii. D. Phil. Thesis, University of Alberta, Edmonton, Canada.

Messier F. 1994. Ungulate population models with predation: a case study with the North American moose. Ecology 75: 478-488. DOI: 10.2307/1939551.Nauhton D. 2012. The natural history of Canadian mammals. Toronto: University of Toronto Press.

Norrdahl K, Korpimäki E. 2000. Do predators limit the abundance of alternative prey? Experiments with vole eating avian and mammalian predators. Oikos 91: 528-540. DOI: 10.1034/j.1600-0706.2000.910315.x.

O'Donoghue M, Boutin S, Krebs CJ, Hofer EJ. 1997. Numerical responses of coyotes and lynx to the snowshoe hare cycle. Oikos 80: 150-162. DOI: 10.2307/3546526.

O'Donoghue M, Boutin S, Krebs C.J., Zuleta G, Murray DL, Hofer EJ. 1998a. Functional responses of coyotes and lynx to the snowshoe hare cycle. Ecology 79: 1193-1208. DOI: $10.2307 / 176736$.

O'Donoghue M, Boutin S, Krebs CJ, Murray DL, Hofer EJ. 1998b. Behavioural responses of coyotes and lynx to the snowshoe hare cycle. Oikos 82: 169-183. DOI: 10.2307/3546927.

Odum, HT, Allee WC. 1954. A note on the stable point of populations showing both intraspecific cooperation and disoperation. Ecology 35: 95-97. DOI: 10.2307/1931412.

Otis DL, Burnham KP, White GC, Anderson DR. 1978. Statistical inference from capture data on closed animal populations. Wildlife monographs 62: 3-135. DOI: 10.2307/2287873. 
452 Pech RP, Sinclair ARE, and Newsome AE. 1995. Predation models for primary and secondary 453 prey species. Wildlife Research 22: 55-63.DOI: 10.1071/WR9950055.

454 Pollock KH, Nichols JD, Brownie C, Hines JE. 1990. Statistical inference for capture-recapture 455 experiments. Wildlife monographs 107: 3-97. DOI: 10.2307/2532321.

456 Price LW. 1971. Geomorphic effect of the Arctic ground squirrel in the alpine environment. 457 Geografiska Annaler. Series A, Physical Geography 53: 100-106. DOI: 10.2307/520669. 458 Reed JM, Dobson AP. 1993. Behavioural constraints and conservation biology: conspecific 459 attraction and recruitment. Trends in Ecology and Evolution 8: 253-256. DOI: $460 \quad 10.1016 / 0169-5347(93) 90201-Y$.

461 Rexstad E, Burnham KP. 1991. User's guide for interactive program CAPTURE. Color. 462 Cooperative Fish and Wildlife Research Unit. Available at: http://www.mbr463 pwrc.usgs.gov/software/doc/capture/capture.htm.

464 Sheriff MJ, Fridinger RW, Tøien Ø, Barnes BM, Buck CL. 2013. Metabolic rate and 465 prehibernation fattening in free-living arctic ground squirrels. Physiological and $466 \quad$ Biochemical Zoology 86: 515-527. DOI: 10.1086/673092.

467 Sherman PW. 1977. Nepotism and the evolution of alarm calls. Science 197: 1246-1253. DOI: $468 \quad 10.1126 /$ science.197.4310.1246.

469 Sibly RM, Hone J. 2002. Population growth rate and its determinants: an overview.

$470 \quad$ Philosophical Transactions of the Royal Society B: Biological Sciences 357: 1153-1170.

$471 \quad$ DOI: $10.1098 /$ rstb.2002.1117.

472 Sinclair ARE, Krebs CJ. 2001. Trophic interaction, community organization, and the kluane 473 ecosystem. Ecosystem Dynamics of the Boreal Forest. In: Krebs CJ, Boutin S, Boonstra R, 474 ed. Ecosystem Dynamics of the Boreal Forest. Oxford: Oxford University Press, 179-214. 475 Available at: http://www.zoology.ubc.ca/ krebs/kbook.html.

476 Sinclair ARE, Krebs CJ. 2002. Complex numerical responses to top-down and bottom-up 477 processes in vertebrate populations. Philosophical Transactions of the Royal Society of $478 \quad$ London B: Biological Sciences 357.1425: 1221-1231. Doi: 10.1098/rstb.2002.1123.

479 Sinclair ARE, Pech RP. 1996. Density dependence, stochasticity, compensation and predator 480 regulation. Oikos 75: 164-173. DOI: $10.2307 / 3546240$. 
481 Sinclair ARE, Pech RP, Dickman CR, Hik D, Mahon P, Newsome A.E. 1998. Predicting effects

of predation on conservation of endangered prey. Conservation Biology 12: 564-575. DOI: 10.1111/j.1523-1739.1998.97030.x.

Stephens PA, Sutherland WJ. 1999. Consequences of the Allee effect for behaviour, ecology and conservation. Trends in Ecology and Evolution 14: 401-405. DOI: 10.1016/S01695347(99)01684-5.

Sutherland WJ. 1988. Predation may link the cycles of lemmings and birds. Trends in Ecology \& Evolution 3: 29-30.

Turkington R., John E, Krebs CJ, Dale MRT, Nams VO, Boonstra R, Boutin S, Martin K, Sinclair ARE, Smith JNM. 1998. The effects of NPK fertilization for nine years on the vegetation of the boreal forest in northwestern Canada. Journal of Vegetation Science 9: 333-346. DOI: $10.2307 / 3237098$.

Turkington R., John E, Watson S, Seccombe-Hett P. 2002. The effects of fertilization and herbivory on the herbaceous vegetation of the boreal forest in north-western Canada: a 10year study. Journal of Ecology 90: 325-337. DOI: 10.1046/j.1365-2745.2001.00666.x.

Werner JR. 2015. Factors Governing the Distribution and Abundance of Arctic Ground Squirrels. Arctic 68: 521-526. DOI: 10.14430/arctic4537.

Werner JR., Donker SA, Krebs CJ, Sheriff MJ, and Boonstra R. 2015a. Arctic Ground Squirrel Population Collapse in the Boreal Forests of the Southern Yukon. Wildlife Research 42: 176-184. DOI: 10.1071/WR14240.

Werner JR, Krebs CJ, Donker SA, Sheriff MJ. 2015b. Forest or meadow: the consequences of habitat on female arctic ground squirrel condition. Canadian Journal of Zoology 93: 791797. DOI: 10.1139/cjz-2015-0100.

Wheeler HC, and Hik DS. 2012. Arctic ground squirrels Urocitellus parryii as drivers and indicators of change in northern ecosystems. Mammal Review 43: 238-255. DOI: 10.1111/j.1365-2907.2012.00220.x

White GC, Anderson DR, Burnham KP, Otis DL. 1982. Capture-recapture and removal methods for sampling closed populations. Los Alamos, New Mexico: Los Alamos Nat. Lab. Publ. LA-8787-NERP. 

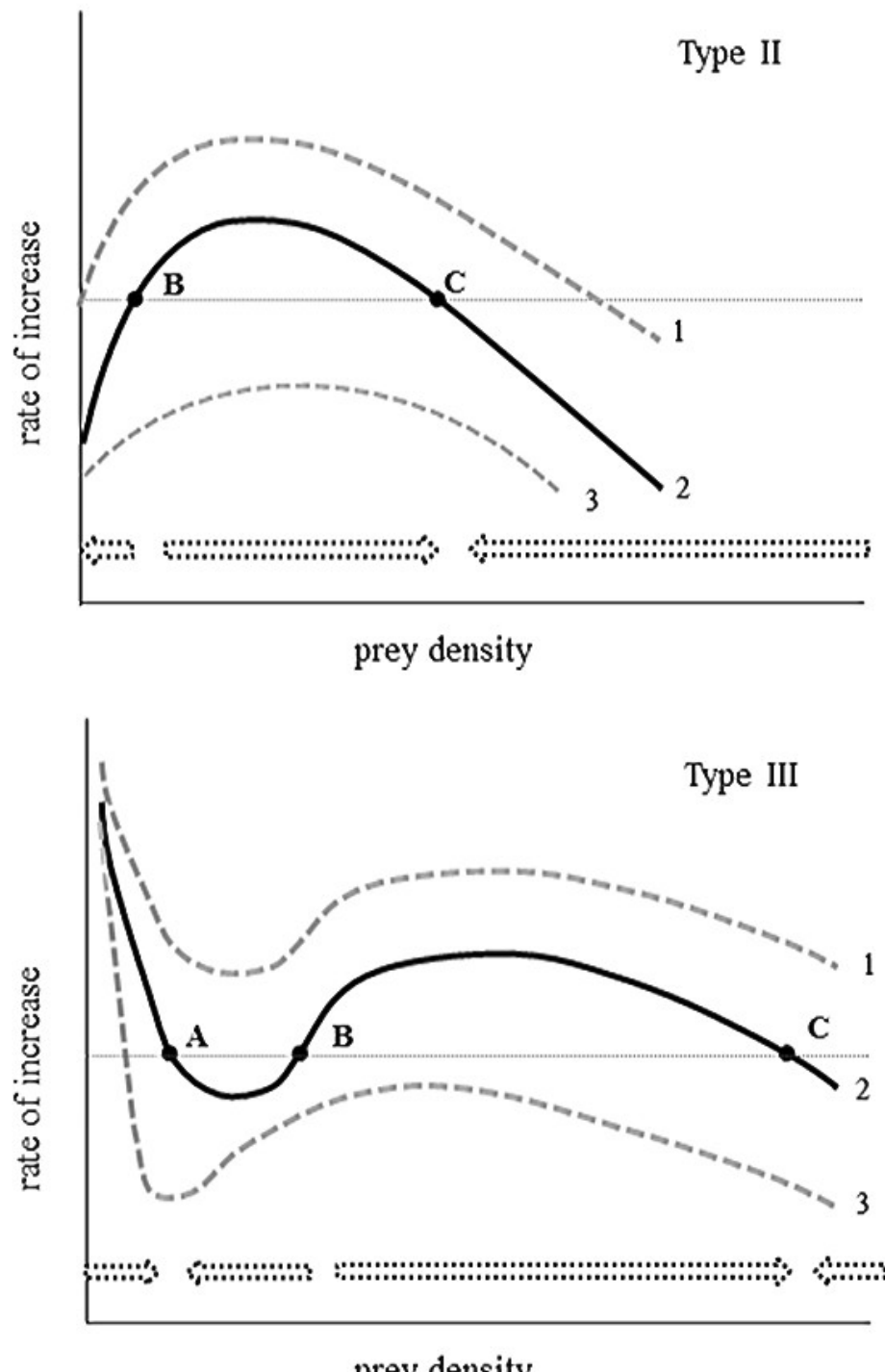

prey density

Figure 1: An illustration of the instantaneous rate of change for a prey population experiencing varying levels of Type II and Type III predation. Arrows represent direction of projected population change relative to stable equilibria $(a, c)$ and an unstable boundary threshold $(b)$. Curves 1 and 3 represent different levels of predation rate $(1=$ lowest; $3=$ highest $)$. Key distinguishing features for a Type II is for declining prey population growth at low prey density, but for Type III a lower stable equilibria results from positive population growth at low numbers. Adapted from Sinclair and Krebs (2002). 


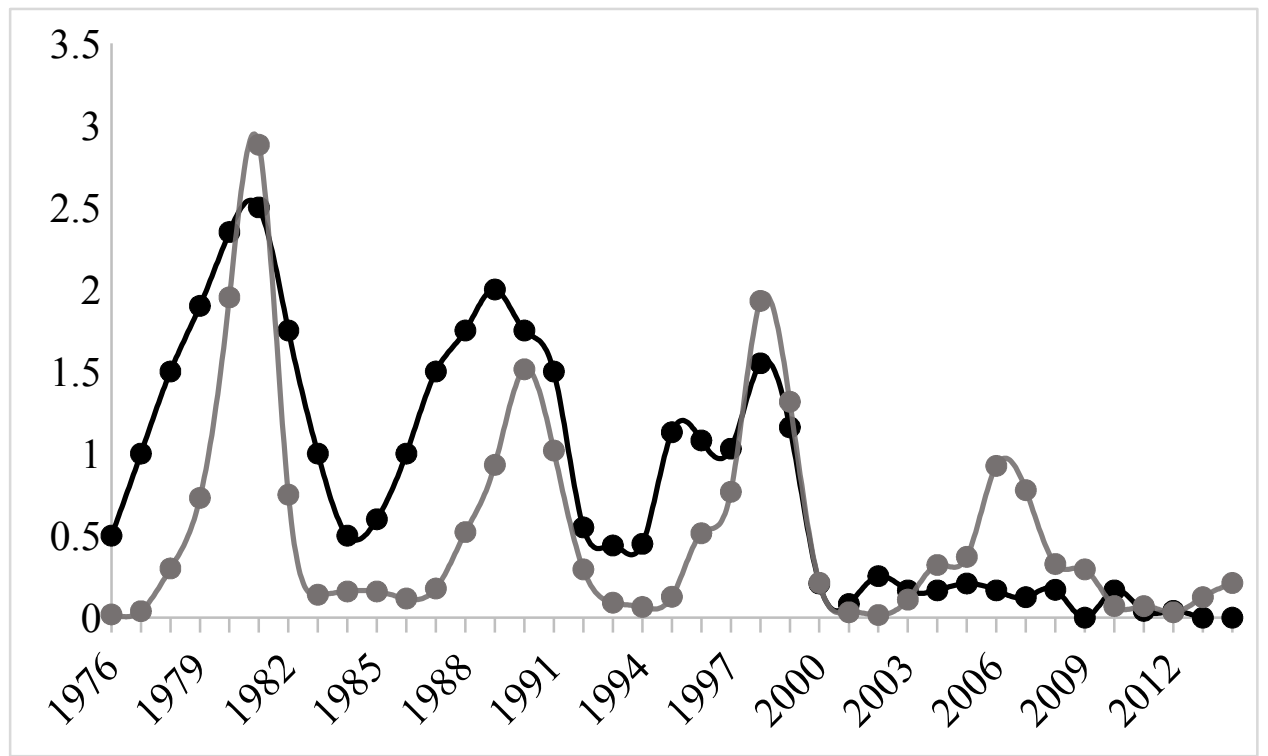

Figure 2: Changes in the spring density of arctic ground squirrels in two live-trapping grids in the boreal forest at Kluane Lake since 1977 (filled circles) and the spring density of snowshoe hares in the same habitat (open circles). Data from Werner et al. 2015; AGS density estimates for 1977-1989 are based on an index of abundance, while 1990-2015 are mark-recapture estimates. Grey vertical bars are $95 \%$ confidence limits. 

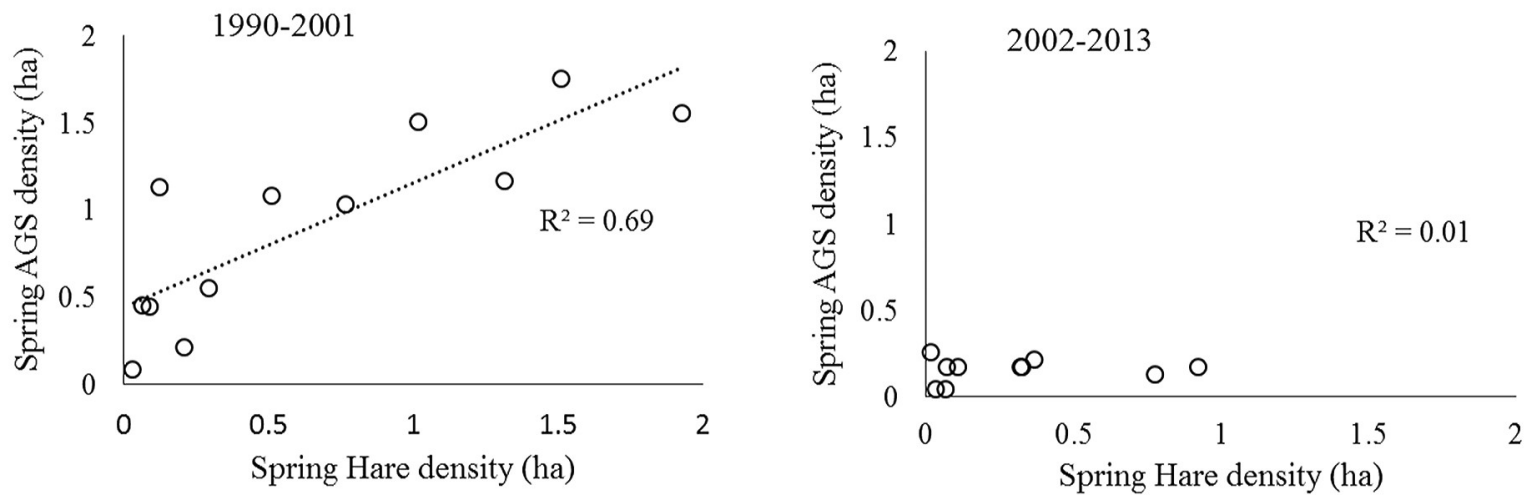

Figure 3: The historical relationship between spring density of sympatric populations of snowshoe hare and arctic ground squirrels in the boreal forests of the Kluane region, SW Yukon. The time periods represent conditions before and after the population collapse of ground squirrels. A high correlation is consistent with apparent competition between the two species mediated by shared predators. 


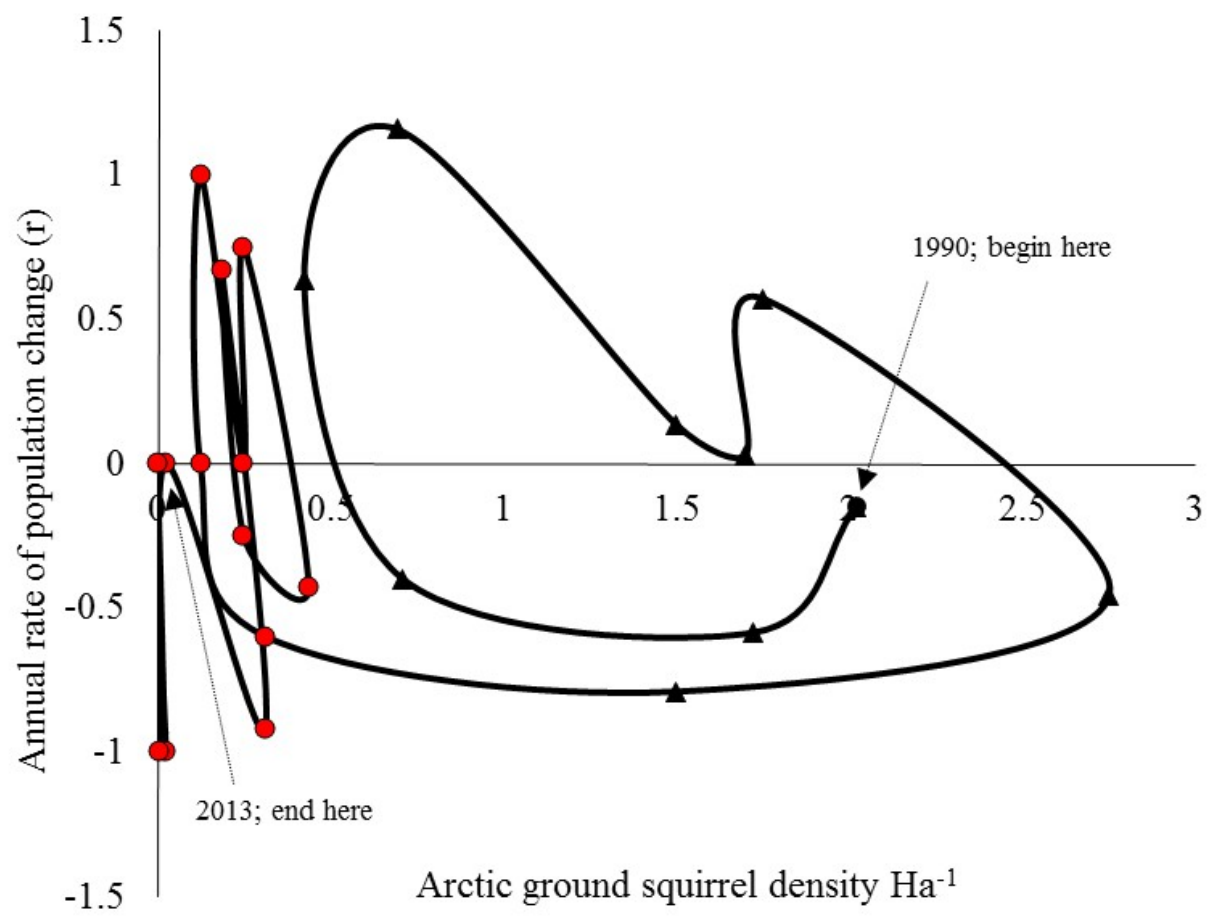

Figure 4: Rate of increase (r) for arctic ground squirrels in relation to its population density between 1990-2013 (annual spring trapping records; Kluane, SW Yukon). The data comprise one cycle and subsequent non-cyclic dynamics post 2000. The rate of AGS increase follows a different path from that of the increase phase due to apparent competition with the snowshoe hare (first 10 data points). The rates exhibit unstable dynamics below a density threshold of $0.5 /$ ha, that end in eventual localised extinction (final 13 data points). 


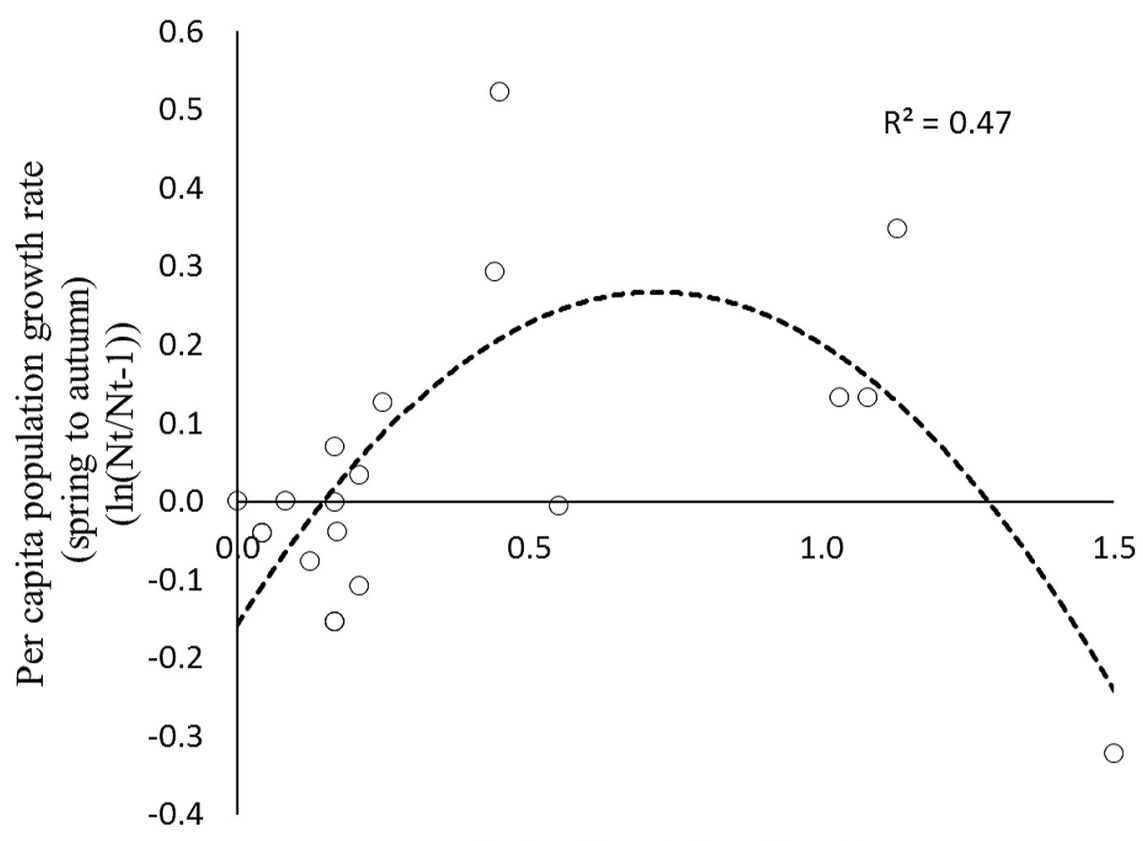

Spring Population Density

Figure 5: The instantaneous rate of population increase for the arctic ground squirrel during the non-hibernation period (May_-August) plotted against spring population density 1990-201. This hump-shaped relationship is indicative of type II predation given that nearly all mortality during these months is due to predation. 